\title{
Benefits of a Single-Person Spacecraft for Weightless Operations
}

\author{
Brand Norman Griffin
}

Gray Research, Jacobs Engineering ESTS Group, Huntsville, Alabama, 35806; Ph (256) 544-2427; email: brand.n.griffin@nasa.gov

\begin{abstract}
Historically, less than 20 percent of crew time related to extravehicular activity (EVA) is spent on productive external work. ${ }^{1}$ A single-person spacecraft with 90 percent efficiency provides productive new capabilities for maintaining the International Space Station (ISS), exploring asteroids, and servicing telescopes or satellites. With suits, going outside to inspect, service or repair a spacecraft is time-consuming, requiring pre-breathe time, donning a fitted space suit, and pumping down an airlock. For ISS, this is between 12.5 and 16 hours for each EVA, not including translation and work-site set up. The work is physically demanding requiring a day of rest between EVAs and often results in suit-induced trauma with frequent injury to astronauts' fingers ${ }^{2}$. For maximum mobility, suits use a low pressure, pure oxygen atmosphere. This represents a fire hazard and requires pre-breathing to reduce the risk of decompression sickness (bends). With virtually no gravity, humans exploring asteroids cannot use legs for walking. The Manned Maneuvering Unit offers a propulsive alternative however it is no longer in NASA's flight inventory.

FlexCraft is a single person spacecraft operating at the same cabin atmosphere as its host so there is no risk of the bends and no pre-breathing. This allows rapid, any-time access to space for repeated short or long EVAs by different astronauts. Integrated propulsion eliminates hand-over-hand translation or having another crew member operate the robotic arm. The one-size-fits-all FlexCraft interior eliminates the suit part inventory and crew time required to fit all astronauts. With a shirtsleeve cockpit, conventional displays and controls are used and because the work is not strenuous no rest days are required. Furthermore, there is no need for hand tools because manipulators are equipped with force multiplying endeffectors that can deliver the precise torque for the job.
\end{abstract}

\footnotetext{
${ }^{1}$ Advanced EVA Roadmaps and Requirements, Richard Fullerton, NASA, JSC, ICES01, 2001-012200

${ }^{2}$ Probability of Spacesuit-Induced Fingernail Trauma Is Associated with Hand Circumference, Opperman, Roedolph A.; Waldie, James M. A.; Natapoff, Alan; Newman, Dava J.; Jones, Jeffrey A., Aviation, Space, and Environmental Medicine, Volume 81, Number 10, October 2010 , pp. 907913(7), Aerospace Medical Association
} 


\title{
Benefits of a Single-Person Spacecraft \\ for Weightless Operations \\ (Stop Walking and Start Flying)
}

\author{
Brand N. Griffin ${ }^{1}$ \\ Gray Research, Engineering, Science, and Technical Services Contract, \\ 655 Discovery Drive Ste. 300, Huntsville, AL 35806 U.S.A
}

\begin{abstract}
Historically, less than 20 percent of crew time related to extravehicular activity (EVA) is spent on productive external work. For planetary operations space suits are still the logical choice; however, for safe and rapid access to the weightless environment, spacecraft offer compelling advantages. FlexCraft, a concept for a single-person spacecraft, enables anytime access to space for short or long excursions by different astronauts. For the International Space Station (ISS), going outside is time-consuming, requiring pre-breathing, donning a fitted space suit, and pumping down an airlock. For each ISS EVA this is between 12.5 and 16 hours. FlexCraft provides immediate access to space because it operates with the same cabin atmosphere as its host. Furthermore, compared to the space suit pure oxygen environment, a mixed gas atmosphere lowers the fire risk and allows use of conventional materials and systems. For getting to the worksite, integral propulsion replaces hand-overhand translation or having another crew member operate the robotic arm. This means less physical exertion and more time at the work site. Possibly more important, in case of an emergency, FlexCraft can return from the most distant point on ISS in less than a minute. The one-size-fits-all FlexCraft means no on-orbit inventory of parts or crew time required to fit all astronauts. The shirtsleeve cockpit uses conventional displays and controls which means the work is not strenuous, there is no suit trauma and rest days are not required. Furthermore, there is no need to collect hand tools because manipulators are equipped with force multiplying end-effectors that can deliver the precise torque for the job. FlexCraft is an efficient solution for asteroid exploration allowing all crew to use one vehicle with no risk of contamination. And, because FlexCraft is a vehicle, its design offers better radiation and micro-meteoroid protection than space suits.
\end{abstract}

\section{Nomenclature}

\begin{tabular}{|c|c|c|c|}
\hline$E M U$ & $=$ extravehicular mobility unit & $M M U$ & $=$ manned maneuvering unit \\
\hline EVA & $=$ extravehicular activity & MSS & $=$ mobile servicing system \\
\hline GCR & $=$ galactic cosmic ray & $N B L$ & $=$ neutral buoyancy laboratory \\
\hline GEO & $=$ geosynchronous orbit & $P M A$ & $=$ pressurized mating adaptor \\
\hline ISS & $=$ international space station & $S A A$ & $=$ south Atlantic anomaly \\
\hline$L C D$ & $=$ liquid crystal display & SCOUT & space construction and orbital utility transport \\
\hline MAWS & $=$ manned autonomous workstation & SPE & $=$ solar particle event \\
\hline MFR & $=$ manipulator foot restraint & SSRMS & $=$ space station remote manipulator system \\
\hline$M M O D$ & $=$ micrometeoroid orbital debris & WEI & $=$ work efficiency index \\
\hline
\end{tabular}

\footnotetext{
${ }^{1}$ Senior Engineer, Gray Research, Jacobs Engineering ESTS Group, Huntsville, AL, Senior Member.
} 


\section{Introduction}

UTOMOBILE pioneer Henry Ford is reputed to have said, " If I asked people what they wanted, they would have said faster horses." Better propellers are no match for jet engines and better space suits will not significantly improve weightless EVA. However, a single-person spacecraft does offer promise for step-function improvements for weightless operations.

The contributions made by astronauts working in space suits cannot be overstated. Lunar samples have been collected, missions saved, and the International Space Station (ISS) assembled. However, the post-Shuttle era suggests a future with two paths. One with astronauts in space suits for human planetary operations and the other with piloted spacecraft for safer, cost-effective and more efficient weightless operations. This is a bold forecast because most see suited EVA as the only solution to external operations. An alternative is FlexCraft, a concept for a single person spacecraft offering real benefits with immediate and long-range application for ISS, satellite servicing and asteroid exploration. Table 1 summarizes the advantages compared to ISS suited operations.

Table 1 Summary of Benefits

\begin{tabular}{|c|c|c|}
\hline Item & ISS Suited Operations & FlexCraft \\
\hline Overhead (less is better) & $12.5-16$ hrs & $0.3 \mathrm{hrs}$ \\
\hline $\begin{array}{l}\text { Work Efficiency Index } \\
\text { (higher is better) }\end{array}$ & $\begin{array}{l}0.39 \text { - } 0.43 \text { Cycle Ergometer with Vibration Isolation } \\
\text { and Stabilization System (CEVIS) }\end{array}$ & 12.0 (4 hr. excursion) \\
\hline Translation & Hand-over-hand or crew operated manipulator & Fly directly to site \\
\hline Materials/Components & $\begin{array}{l}\text { Limited materials, additional cost and time for } 100 \% \text { O2 } \\
\text { environment certification }\end{array}$ & $\begin{array}{l}\text { Same as host (materials and } \\
\text { electronics) }\end{array}$ \\
\hline Operating Atmosphere & Low pressure, $100 \%$ Oxygen & Same as host (direct access) \\
\hline Decompression Sickness & Risk of getting “bends” (prebreathing required) & No risk (no prebreathing) \\
\hline Fatigue & $\begin{array}{l}\text { Physically strenuous, high metabolic activity (Requires } \\
\text { day of rest between EVAs) }\end{array}$ & No rest required \\
\hline Trauma & Abrasions, bruises, delaminated finger nails & None \\
\hline Hydration and Nutrition & Helmet water spigot, no food & Hands-in, water bottle and food \\
\hline Airlock & STS airlock (440 kg) ISS Quest (8,241 kg) & None \\
\hline Pump power & Pump down for airlock & None \\
\hline Restraints & Foot restraints, tethers, hand holds & None \\
\hline Design for EVA ops & $\begin{array}{l}\text { Load path for restraints, smooth snag free finish, } \\
\text { labeling, EVA kick loads }\end{array}$ & None \\
\hline Displays and Controls & External chest mounted, glove operations & Shirt sleeve (conventional ops) \\
\hline Tools & Glove operated & Force multiplying end-effectors \\
\hline Potential Contamination & Hydrazine, asteroid dust contaminate cabin air & None \\
\hline Sizing & Inventory of components, custom gloves & None \\
\hline MMOD & Additional materials and layering & Whipple bumper (better) \\
\hline Radiation Protection & Additional layers restrict mobility & Polyethylene jacket or liner \\
\hline Duration & Long (planned for 7 hrs.; routinely last 8 hrs.) & Short or long excursions \\
\hline
\end{tabular}

* “A \$150 Polar heart rate monitor may require \$200K (or more) of engineering testing, analysis and certification before it can be accepted for use inside the Space Suit” Glenn Lutz, EVA Systems Project Office, Johnson Space Center, 13 February 2007 


\section{A. The Idea is Not New}

Visions of a single-person spacecraft are not new (Fig.1). In 1954, Wernher vonBraun presented a concept for a bottle suit and the 1968 movie 2001 A Space Odyssey featured a pod shaped spacecraft. In addition, there have been engineering studies with different configurations; some with gloved arms, some with manipulators and some with both. Yet, after all these years, not one has flown.

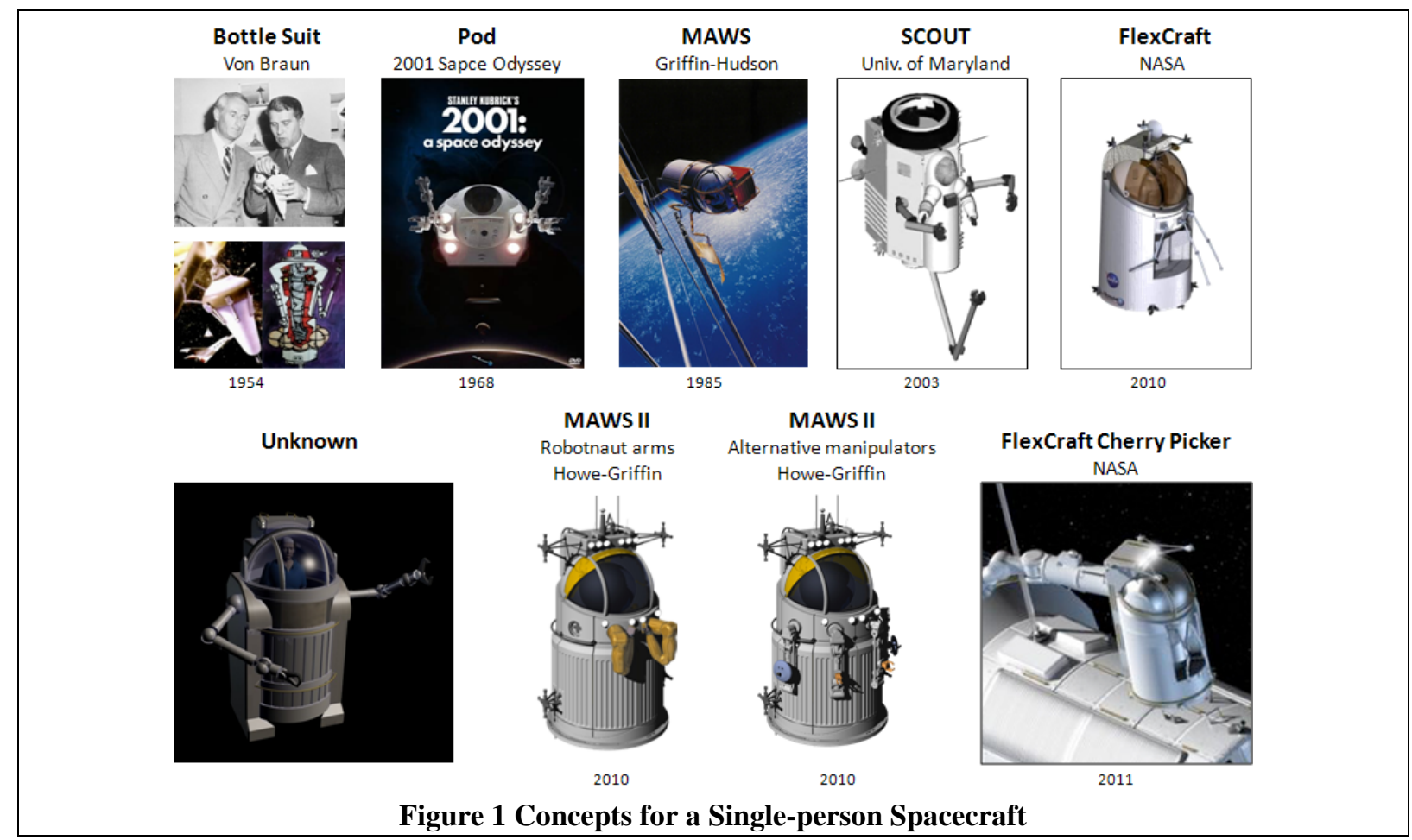

II. Single-person Spacecraft: FlexCraft

FlexCraft draws its name from the Flexible Path approach to human exploration and is a single-person spacecraft designed for repair, servicing and exploration (Fig. 2). It is shaped around the astronaut's weightless, neutral body posture and designed according the five following constraints: 1 . Operate within close proximity of a host spacecraft (ISS or transfer vehicle), 2. Have the same cabin atmosphere as the host, 3. Includes integrated propulsion, 4. Use manipulators, rather than gloves, and 5 . One size fits all.

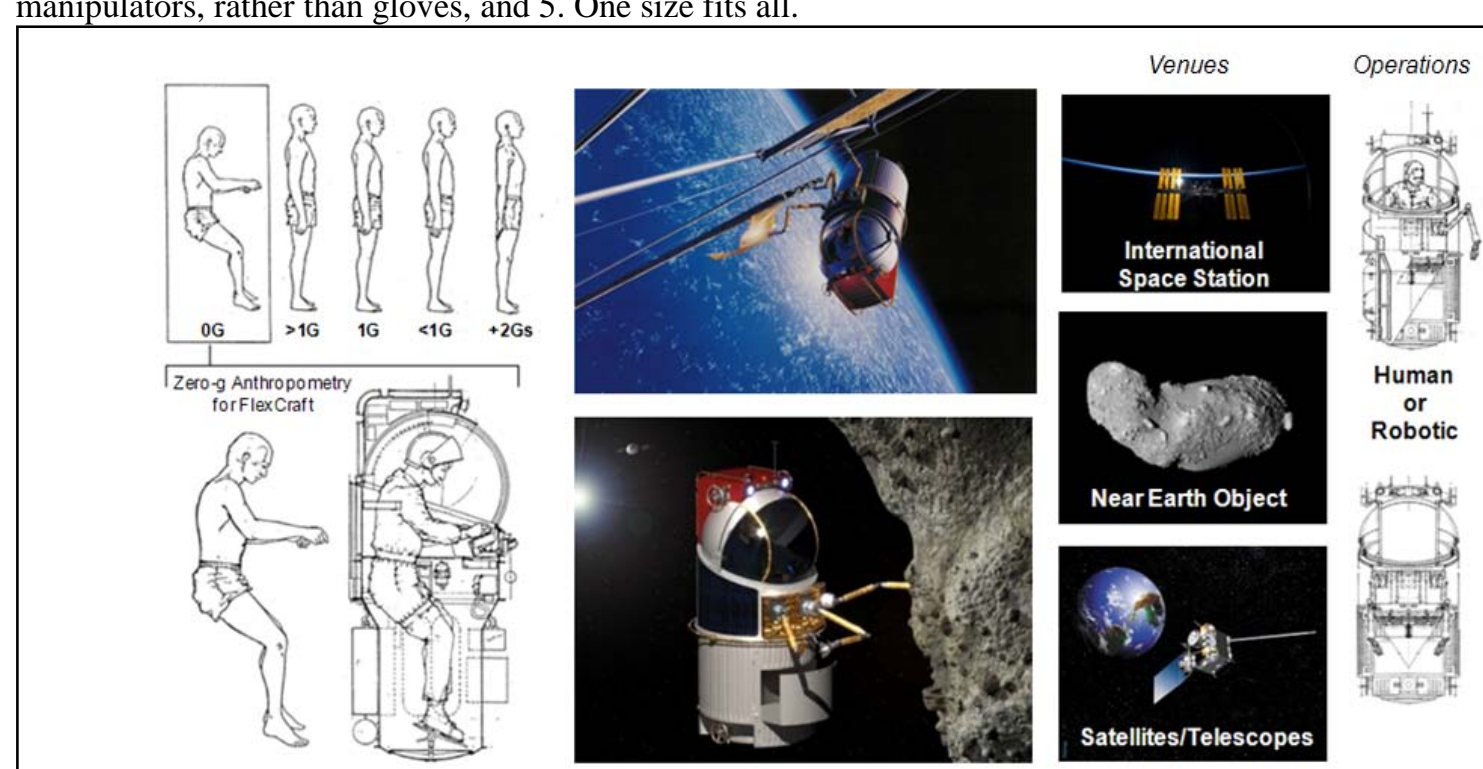

Figure 2 The FlexCraft can be piloted or teleoperated for work in multiple environments

3

American Institute of Aeronautics and Astronautics 


\section{B. ISS Maintenance and Repair}

The decision to extend the on-orbit life of the ISS means additional maintenance for the 13-year-old station. Life critical systems such as the solar arrays and radiators are exposed to environmental degradation from atomic oxygen, and radiation as well as impact from micro-meteoroids and debris. For suited astronauts, maintenance takes time and effort to prepare, collect tools and translate to the worksite. Furthermore, some systems are difficult if not impossible to reach (See Fig. 3). In contrast, astronauts using FlexCraft have immediate access to space, can fly

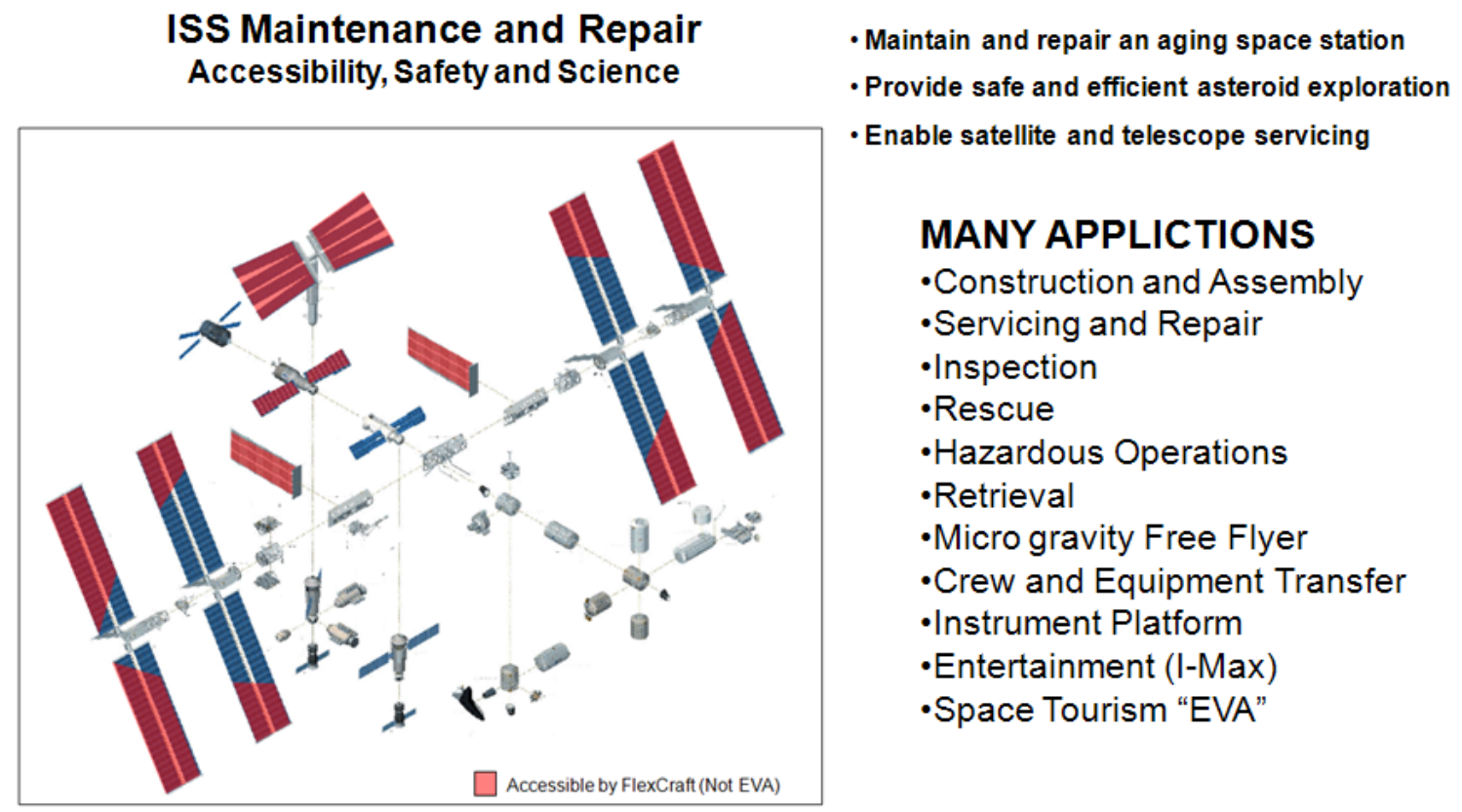

Figure 3 Without the Shuttle, FlexCraft provides the next generation capabilities for servicing and repair

directly to the worksite and use on-board manipulator tools for repair. Without the Shuttle transporting space suits, this new capability represents an important transition to the next generation of external operations not only for ISS, but have many other applications for exploration and servicing.

\section{The Dominating Influence of Pressure Gloves}

Much of space suit design is determined by gloves. On Earth we use the large muscles in the legs for walking. Space "walking" uses the smaller arm and hand muscles to manage approximately $205 \mathrm{~kg}$ (450 lbs) mass. In addition to "walking," hands are also used for manipulation and operating tools. This means that glove fit and operation are essential to productive EVA. Much money and time has gone into glove development however,

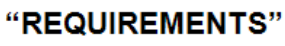

-Dependence on arms and gloves -Hands for translation, manipulation \& tools - Glove should provide: -Range of motion - Tactile feedback - Low forces (reduced strength) -Minimum fatigue -Comfort

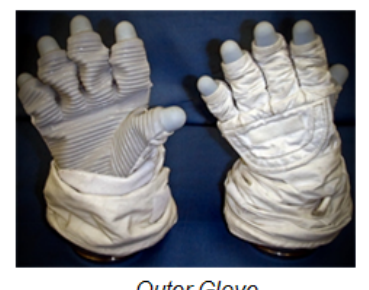

Outer Glove

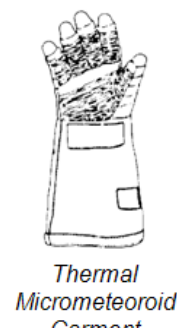

Garment
DESIGN ISSUES

- Good fit important

-Ventilation (moisture control)

-Bulk, layers for:

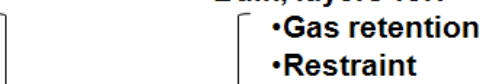

CONFLICTING

-Thermal

-Micrometeoroid

-Puncture

Figure 4 Pressure gloves dominate suit design

4

American Institute of Aeronautics and Astronautics 
there are inherent conflicting requirements. Gloves should provide a good range of motion, tactile feedback, low force, minimum fatigue and comfort. However, the solution requires layers of material that compete with these goals (Fig. 4). Separate layers retain pressure, provide structural restraint, insulate against thermal extremes and protect against micrometeoroids and punctures. Even without pressure, the bulk of these layers inhibits tactile feedback and restricts finger movement. Because high pressure makes the glove fingers stiffer, low pressure designs are preferred. All the atmosphere in the suit is at the same pressure, so glove pressure determines suit pressure. Another reason the preferred design is the low pressure suit is because they minimize leakage, reduce joint torque and facilitate mobility allowing astronauts to reach the work area. For these reasons, the current ISS Extravehicular Mobility Unit (EMU) operates at $29.65 \mathrm{kPa}$ (4.3 psi) which is slightly above the lowest pressure for respiration and requires a pure oxygen breathing atmosphere. The transition between ISS higher pressure, mixed gas atmosphere and the suit has an impact on operations because astronauts must purge the nitrogen in their blood to avoid decompression sickness or the "bends" (Fig. 5). This is important

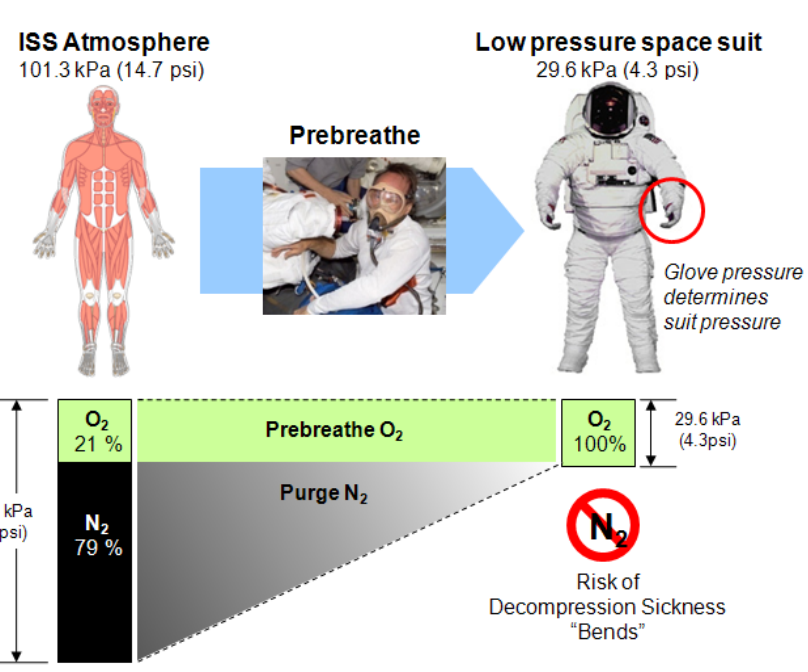

Figure 5 Suits require breathing to avoid the "Bends" because according to the Undersea Hypobaric Medical Society, "the resulting clinical manifestations include joint pains (limb bends), cutaneous eruptions or rashes (skin bends), neurological dysfunction (peripheral or central nervous system bends), cardiorespiratory symptoms and pulmonary edema (chokes), shock and death.” The wear and tear of gloves is a serious concern. "The current state of the art spacesuit gloves, the Phase VI gloves, have an operational life of, and are currently certified for, twenty-five 8-hr EVAs in a dust-free, shuttle- or ISS-based

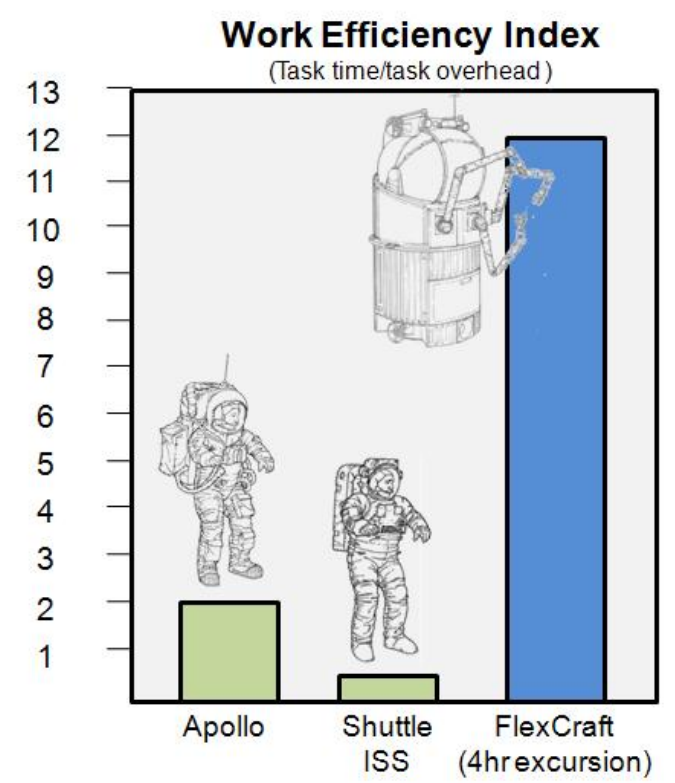

Figure 6 More efficient spacecraft operations microgravity EVA environment. On the ISS, there has been frequent glove damage as well as some minor hand injuries during glove use. Therefore, the gloves have become a lifelimiting component for the entire suit (approximately 6 EVAs for the outer thermal layer)."

For most, there is a tendency to equip a single-person spacecraft with arms and gloves. Unfortunately, these concepts operate with the same limitations as space suits. Prebreathing is required for low pressure glove operation and there is the added complication of fitting the entire design population. This means the eye position, shoulder location, arm length and glove size must be adjusted to fit each astronaut ranging from a $1.5 \mathrm{~m}$ (58.6 in.) tall female to a $1.9 \mathrm{~m}$ (74.8 in.) tall male ${ }^{3}$. Understanding the dominating influence of gloved operations, FlexCraft was intentionally designed to operate with same atmosphere as the host and use manipulators. This means there is no risk of the bends and no need to prebreathe. The common atmosphere concept provides the same benefits whether operating from ISS or a lower pressure transfer vehicle.

In addition to prebreathing, there are suit related tasks that require crew time. The Work Efficiency Index (WEI) is a

\footnotetext{
2 "Extravehicular Activity Technology Development Status and Forecast." Chullen, C., Westheimer, D. T., AIAA 2011-5179

${ }^{3}$ Figure 3.3.1.3-1 Anthropometric Dimensional Data for American Female and Male, NASA, Manned Systems Integration Standards, Vol.1, Section 3 Anthropometry and Biomechanics
} 
common measure of EVA efficiency that represents the task time divided by the overhead time (Fig. 6). For example, a 6 hour EVA with 3.0 hrs overhead has a WEI of 2.0. Apollo astronauts had a WEI of 2.0; however for ISS it is between 0.39 and 0.43 . Suit preparation, prebreathing and airlock operations all contribute to this low number. Flexcraft is a vehicle with automated checkout. Similar to aircraft, it is assumed 20 minutes of crew time would be spent on pre and post flight vehicle activities. With this, a WEI of 12.0 for a 4 hour excursion is conceivable and even higher with longer excursions. For a 7 hr. excursion, the FlexCraft WEI is 21 and assuming 3 times the overhead (60 min.) the WEI is 7, 16 times better than ISS EVA.

\section{FlexCraft Enables Long or Short Excursions}

FlexCraft opens new opportunities for external operations. Without prebreathing or airlock pump down and repressurization, astronauts exit and return quickly with minimal gas loss. Because of the significant overhead time, ISS EVAs are planned to accomplish as much as possible within life support and battery constraints. This typically means long, well scripted EVAs (Fig. 7). In contrast, the low overhead for FlexCraft allows repeated short or long

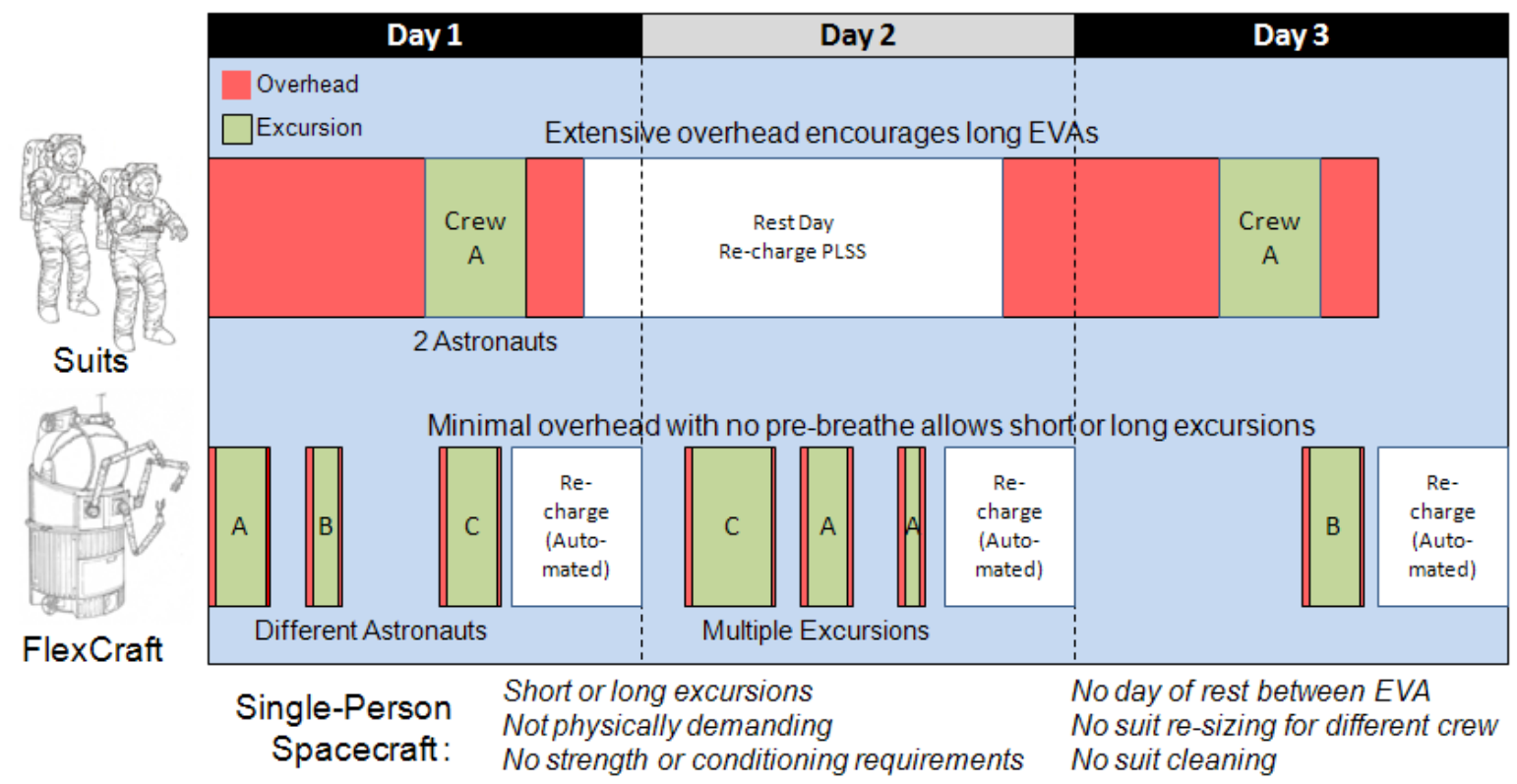

Figure 7 FlexCraft provides frequent short or long excursions with different crews

excursions even using different crew members. Because long EVAs are physically demanding, a rest day is planned between EVAs using the same crew. Operating FlexCraft is not physically demanding therefore a rest day is not necessary.

\section{E. Suit Induced Trauma}

Suit induced trauma is a consequence of EVA that is often overlooked. In 2008, astronauts Carl Walz and Mike Gernhardt presented photographs of swelling, inflammation, and abrasions caused by contact with the inside of the space suit (Fig. 8) ${ }^{4}$. Although there is considerable effort placed on proper sizing, parts of the astronaut's body press and rub against the rigid inner surface of the suit. This causes trauma on the contact points

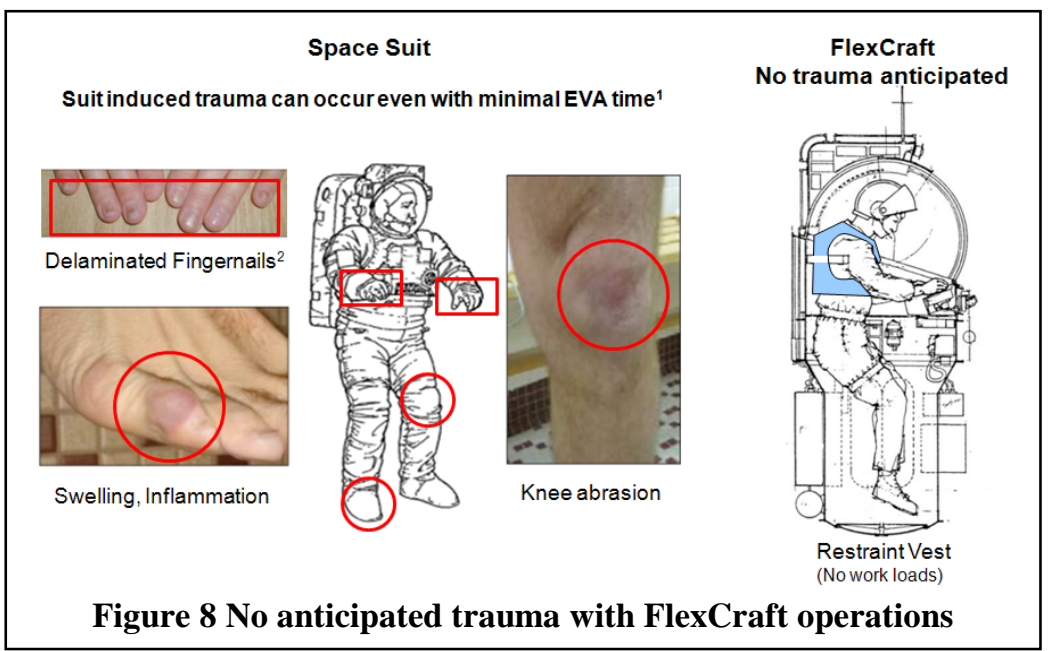

${ }^{4}$ Extravehicular Activity - Challenges in Planetary Exploration, Carl Walz / Mike Gernhardt, 27 February, 2008, Third Space Exploration Conference and Exhibit, Denver, CO 
especially the hands, knees and toes. Hand trauma is a particular concern because grip and finger dexterity are essential for weightless translation, tool operation and getting in and out of the airlock. Probably most significant is the high occurrence of fingernail delamination ${ }^{5}$ with EVA astronauts. This is important because favoring painful or sensitive hands may compromise safety and performance. FlexCraft provides astronauts a shirt sleeve environment; therefore no suit induced trauma is anticipated.

\section{F. Thermal Limits for Gloved Operations}

In space, external hardware can get very hot or cold. EVA astronauts use their hands to touch or grasp latches, valves, tools, hand holds and other external hardware. The problem is that the hand has a narrow thermal tolerance band so gloves must be designed to provide a workable balance between layers of protective insulation while maintaining finger mobility. Many years of EVA construction and repair are evidence that glove designs and procedures are effective. However, there still are operational constraints for grasp time at different temperatures

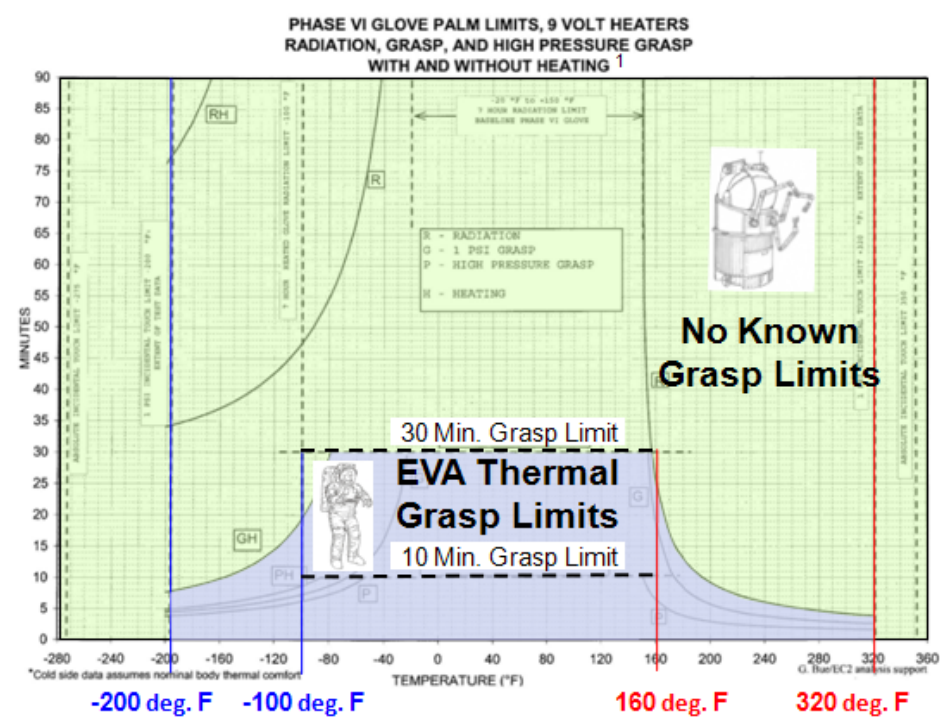

\section{External Hardware Accommodations}

\section{External Glove Touch Temperatures ${ }^{2}$}

EMU gloves shall support EV crewmember hand contact..

EVA tools and support equipment

EVA translation aids, e.g., CETA cart, handholds, handrails

EVA restraints, e.g., tether, tether points

EVA translation paths, e.g., handrails or structure

EVA surfaces indentified for operating, handling, transfer or manipulating hardware

EVA stowage

EVA worksite accommodations, e.g., handholds, ingress aids, EVA lights

EVA ORU handling and transfer equipment

1. EMU Specification SVHS 7800, Rev BZ, pg 83

2. EMU Specification SVHS 7800, Rev BZ, 3.1.1.4.1

Figure 9 Limited grasping time with EVA gloves

(Fig. 9). Even with active heating, touch temperatures are limited to short durations and narrow ranges (-140 to $+240^{\circ} \mathrm{F}$ or -96 to $\left.+116^{\circ} \mathrm{C}\right)^{6}$. FlexCraft uses manipulators designed for the space environment which means they can grasp and hold on to hot or cold hardware for an indefinite period of time.

\section{G. Impact of Operating in a Pure Oxygen Environment}

The low atmospheric pressure in the space suit requires 100 percent oxygen to sustain crew metabolism. This pure oxygen environment represents an elevated fire hazard limiting material selection and equipment operation. For example, a \$150 Polar heart rate monitor may require \$200K (or more) of engineering testing, analysis and certification before it can be accepted for use inside the Space Suit ${ }^{7}$. Figure 10 further describes the impact of increasing the percentage of oxygen in the atmosphere. There are fewer acceptable materials, fire suppression is ineffective, there is rapid fire propagation, and few materials self-extinguish. These limitations not only affect suits, but also the spacecraft systems that fill and store the high pressure tanks used in the backpack. There have been two notable incidents involving high pressure oxygen. The Apollo 1 fire that killed three astronauts is attributed to the $110.3 \mathrm{kPa}$ (16 psia) oxygen environment and in 1980, a suit was destroyed and a technician severely burned during an unmanned test of the EMU (Fig. 11). Perhaps the most far-reaching change of these events is the generation of

\footnotetext{
${ }^{5}$ Probability of Spacesuit-induced Fingernail Trauma is Associated with Hand Circumference, Opperman, R.A, et al, Aviation Space Environmental Medicine, Oct, 2010

${ }_{7}^{6}$ Advanced EVA Roadmaps and Requirements, Richard K. Fullerton, ICES01-2200

${ }^{7}$ Designing for EVA Applications, Gene Lutz, EVA Systems Project Office. Johnson Space Center, 13 February 2007
} 
an agency specification, NSS 1740.15, - Safety Standard for Oxygen and Oxygen Systems that covers materials selection, design, testing, and cleanliness for oxygen systems ${ }^{8}$.

With its mixed gas atmosphere, FlexCraft represents lower fire hazard than space suits. Furthermore, there is no high pressure oxygen system required to pressurize backpack tanks, many more materials are available and there is

\begin{tabular}{|c|c|c|}
\hline & $14.7 \mathrm{psi} / 21 \% \mathrm{O}_{2}$ & $5.2 \mathrm{psi} / 70-100 \% \mathrm{O}_{2}$ \\
\hline Data Base & 10000 reports & 1000 reports \\
\hline Fire Event History & $\begin{array}{l}\text { High temperature spacecraft } \\
\text { events controlled }\end{array}$ & $\begin{array}{l}\text { Apollo } 1(204) \& 13 \text {, } \\
\text { hyperbaric chambers }\end{array}$ \\
\hline Materials Control & Minimal & $\begin{array}{l}\text { Significant, beta bagging, } \\
\text { nonflammable } \\
\text { paints/coatings, aluminum foil } \\
\text { tape, containment, etc. }\end{array}$ \\
\hline Materials Selection & Numerous options & Severely restricted \\
\hline $\begin{array}{l}\text { Off-the-shelf } \\
\text { Hardware }\end{array}$ & Minimal modifications & $\begin{array}{l}\text { Significant design changes, } \\
\text { testing/analysis* }\end{array}$ \\
\hline Fire Detection & Standard & Rapid events \\
\hline Fire Suppression & Standard techniques effective & Ineffective \\
\hline $\begin{array}{l}\text { Propagation } \\
\text { Potential/Self- } \\
\text { Extinguishment }\end{array}$ & Most materials self-extinguish & $\begin{array}{l}\text { Few materials self-extinguish, } \\
\text { rapid propagation }\end{array}$ \\
\hline
\end{tabular}

Dr. Michael D. Pedley, NASA/JSC/ES5, Dennis E. Griffin, NASA/MSFC/EH02

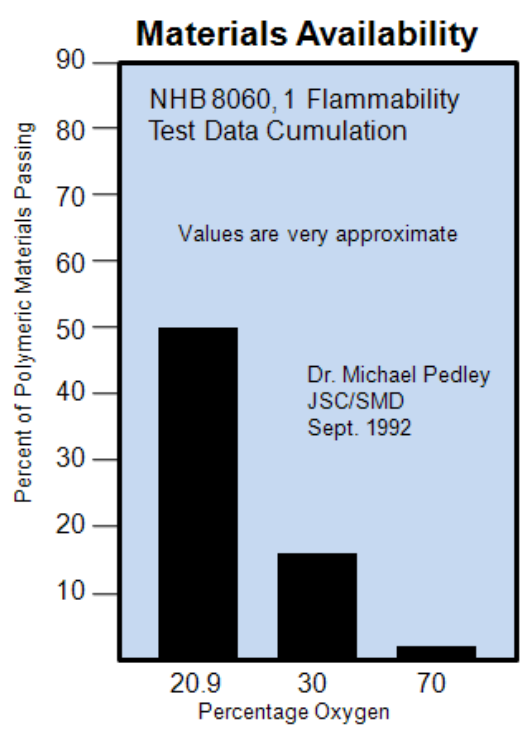

Figure 10 Increased percentage of oxygen elevates fire hazard and restricts acceptable materials

no additional cost for oxygen qualification. FlexCraft operates with the same atmosphere as its host and for ISS; this is $101.36 \mathrm{kPa}(14.7 \mathrm{psi}) 79 \%$ nitrogen and $21 \%$ oxygen. Some proposed space transfer vehicles operate at lower pressures and in this case, FlexCraft would share the same atmosphere.
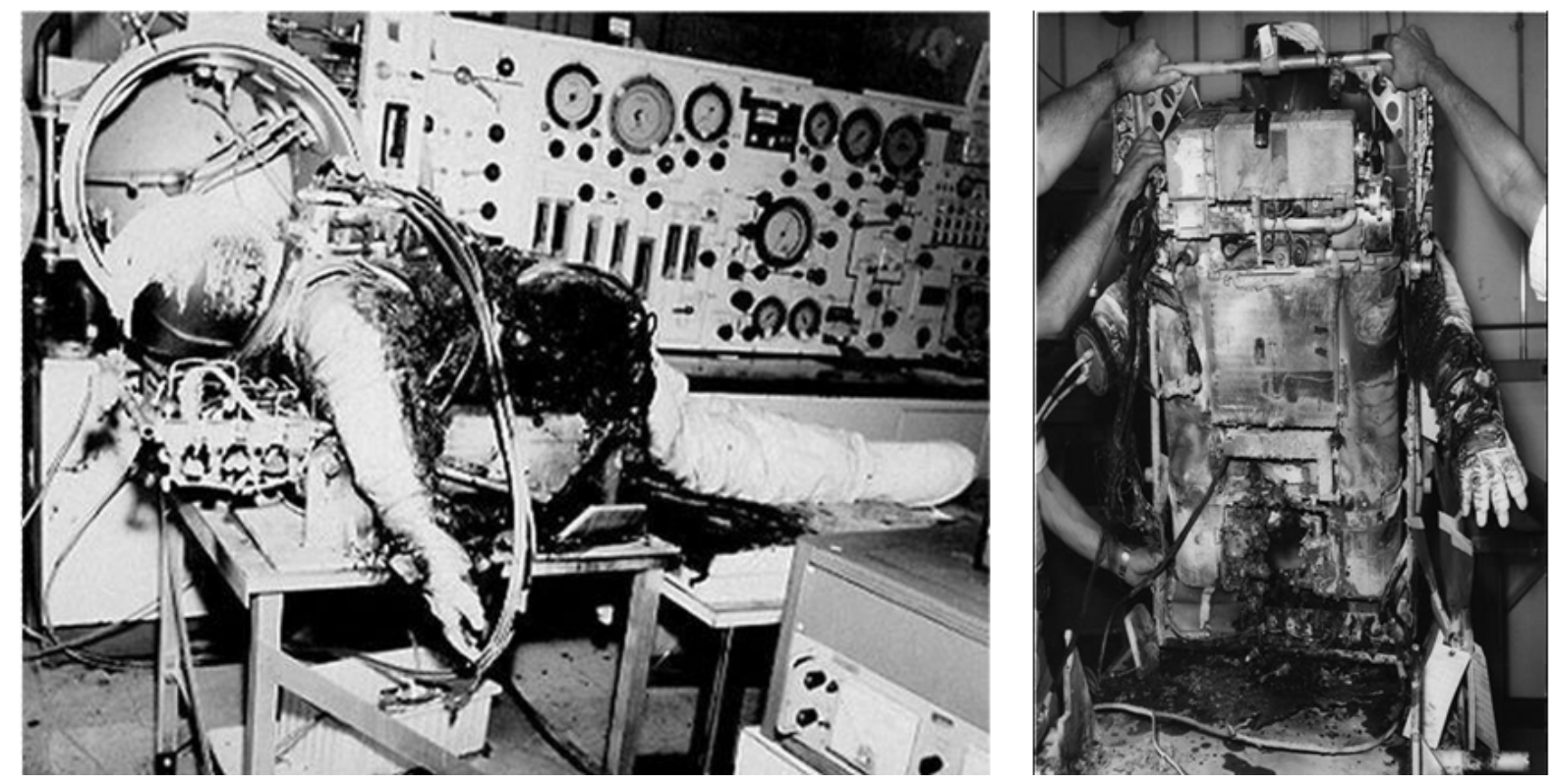

Figure 11 Space Shuttle EMU destroyed in a oxygen fire in April 1980

\footnotetext{
8 “U.S. Spacesuit Knowledge Capture,” AIAA 2011-5199, C. Chullen, J. McMann, K. Dolan, R. Bitterly and C. Lewis
} 


\section{H. Micrometeoroid/Debris protection}

Operating around ISS represents a risk of being hit by a micrometeoroid or debris. ISS uses external layering and separation of materials known as a Whipple bumper to attenuate impact energy ideally preventing pressure hull penetration. Suits cannot provide Whipple bumper protection, but are designed with additional energy absorbing layers. To minimize bulk, these layers not only provide micrometeoroid/debris protection but double as thermal insulation. FlexCraft incorporates Whipple bumpers with multilayer insulation around most of the vehicle (Fig. 12).
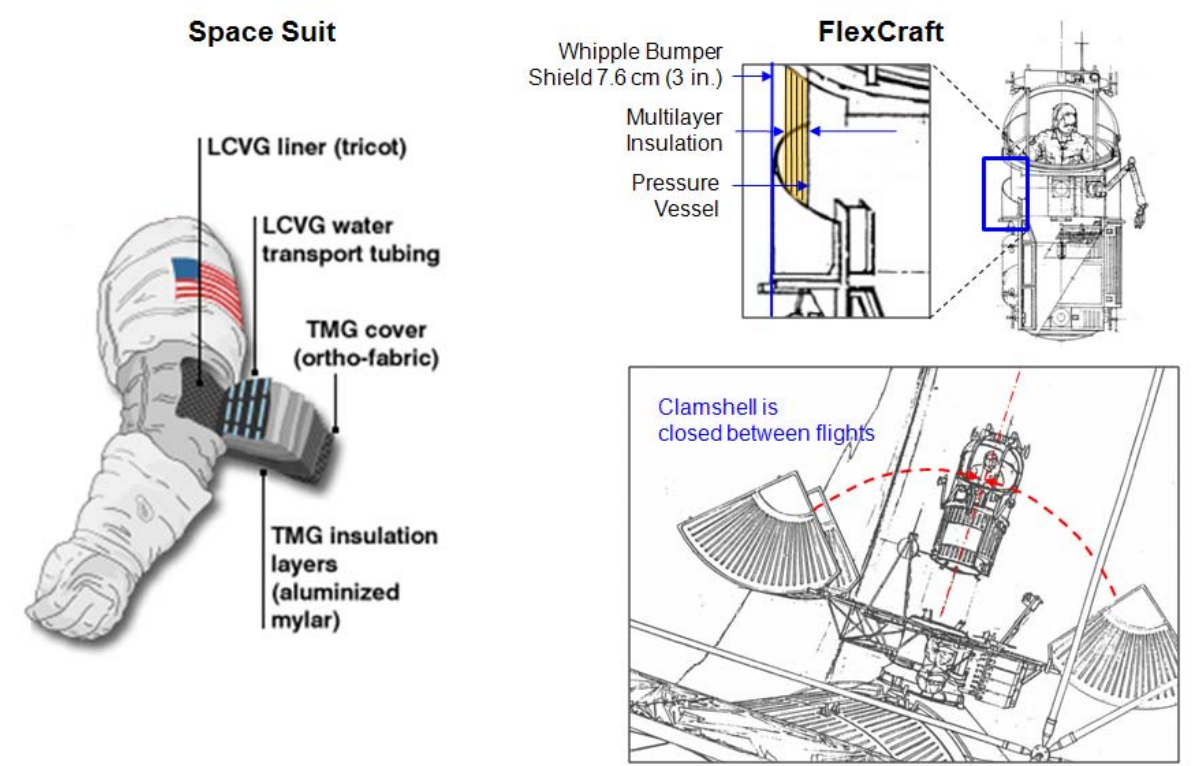

Additional, long-term micrometeoroid/debris and thermal protection will be provided by a lightweight cover. A concept for a clamshell enclosure is shown in Figure 12.

\section{Radiation Protection}

The three sources of radiation are, Galactic Cosmic Rays (GCR), Solar Particle Events (SPE) and trapped radiation in the van Allen belts or South Atlantic Anomaly. The risk associated with GCR radiation is cumulative exposure and therefore affects astronauts on long duration missions. Currently there is no effective protection and neither space suits nor FlexCraft provide any additional protection. SPEs on the other hand, can be lethal, but because there is a warning time, the best approach is retreat to the host shelter and avoid external operations during the events. For ISS, SPEs are not a big concern because it is protected by the Earth's geomagnetic shielding. However, the trapped radiation in the South Atlantic Anomaly (SAA) is a concern for ISS EVA. On occasion, the ISS passes through this region and like SPEs; the best approach is to avoid excursions during these orbits.

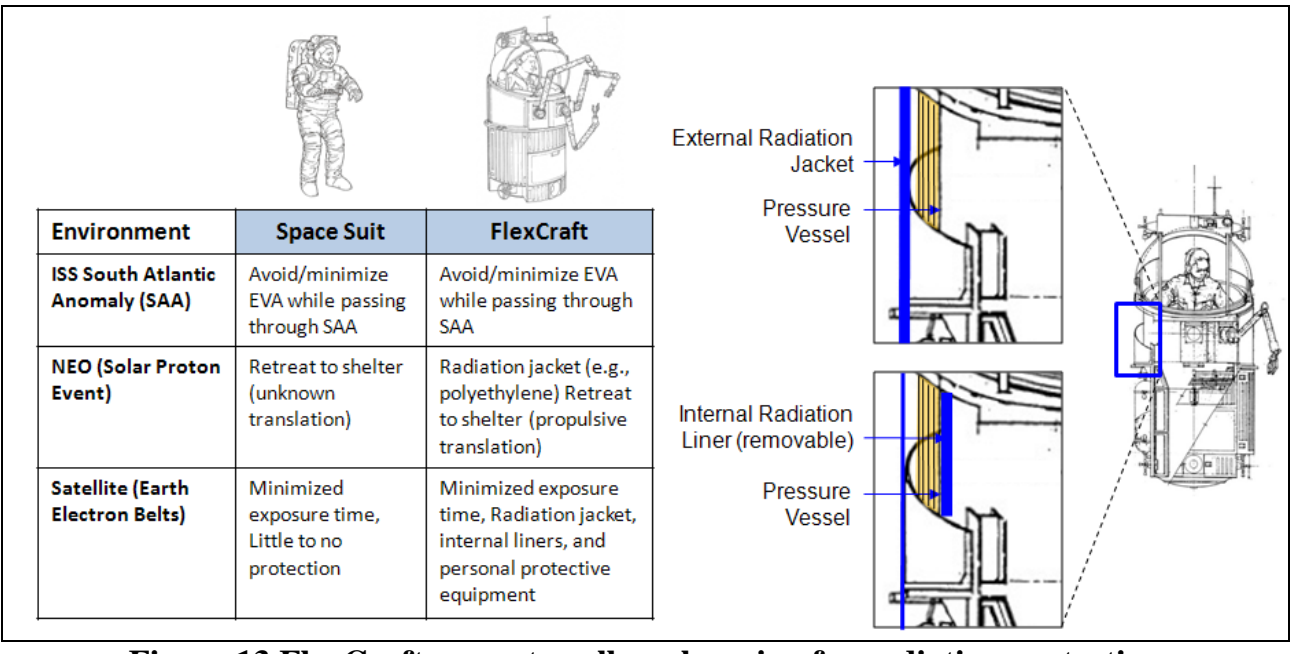

Figure 13 FlexCraft geometry allows layering for radiation protection
Satellite servicing is an emerging market. With more than 150 dead satellites and rocket stages left to drift, a massive orbital cleanup awaits in the Geosynchronous Orbit (GEO). These satellites are in orbits exposed to trapped radiation which represents an operational risk to the crew. For this environment, current space suits offer no 
protection, however FlexCraft provides two opportunities for protection. One is a protective layer wrapped around the exterior and the other attaches a layer as an internal liner. Thermal visors are also covered for upper torso protection. Figure 13 includes a table comparing space suit and FlexCraft approaches for different environments and shows options for FlexCraft protection using polyethylene.

\section{J. Thermal Control}

The space suit active thermal control system is designed to accommodate environmental and equipment heat sources but is largely sized around the astronaut's metabolic activity. This is significant because cooling water usage is directly linked to higher metabolic rates. Waligora et al collected the average metabolic rates for past space missions showing that Skylab EVAs were the highest at $238 \mathrm{kcal} / \mathrm{hr}(944 \mathrm{BTU} / \mathrm{hr})$ with the Space Shuttle at 197

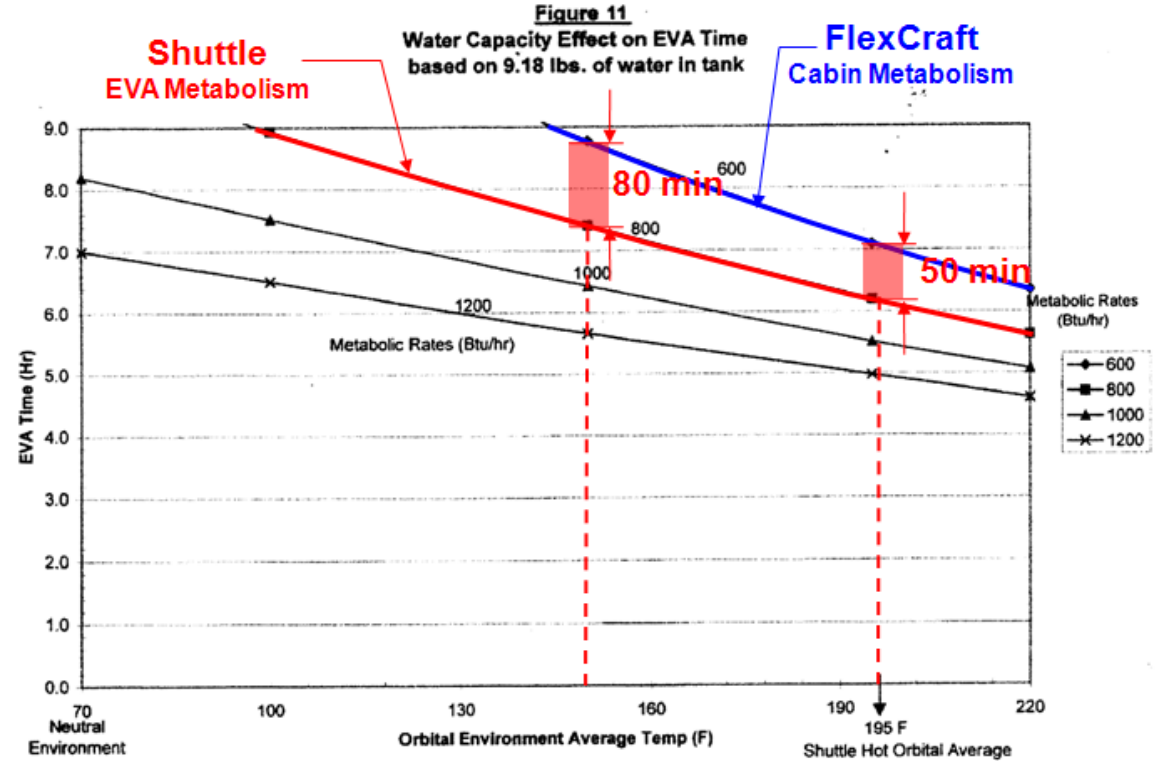

EMU Specification SVHS 7800, Rev BZ, pg 84

Figure 14 Shirt sleeve operations reduce metabolic heat loads and saves water $\mathrm{kcal} / \mathrm{hr}$ (781 BTU/hr). In the Apollo spacecraft, the rate was $151 \mathrm{kcal} / \mathrm{hr}(599$ $\mathrm{BTU} / \mathrm{hr})$. Using the Water Capacity Effect on EVA Time from the EMU Specification shown in Figure 14, at an orbital average temperature of 66 degrees C (150 degrees F) FlexCraft could provide 80 minutes more cooling than the space suit and at the Shuttle hot orbital average of 91 degrees C (195 degrees $\mathrm{F}$ ), there is an additional 50 minutes cooling.

The body cools itself by evaporating sweat, which in turn, puts moisture in the atmosphere. Exhaling is another source of water vapor and both sources increase under strenuous EVA activity. Water moisture is a concern because it condenses on internal surfaces which can obscure visibility and, without treatment, leads to microbial contamination. To control water vapor, suits have a high air flow and astronauts wear a liquid cooling ventilation garment. FlexCraft is designed for shirt sleeve (low metabolic rate) operations and thus avoids the additional accommodations required for the higher metabolic EVA activity.

\section{K. Worksite and Translation} One challenge for weightless EVA, is positioning foot restraints so that astronauts can reach and see the work area (Figure 15). It is important that the restraint clocking, angle and distance from the work area are adjusted to accommodate individual astronaut anthropometry. Foot restraints are attached to rigid structure or on the end of a robot arm, but the objective is to position the crew member so that the task is

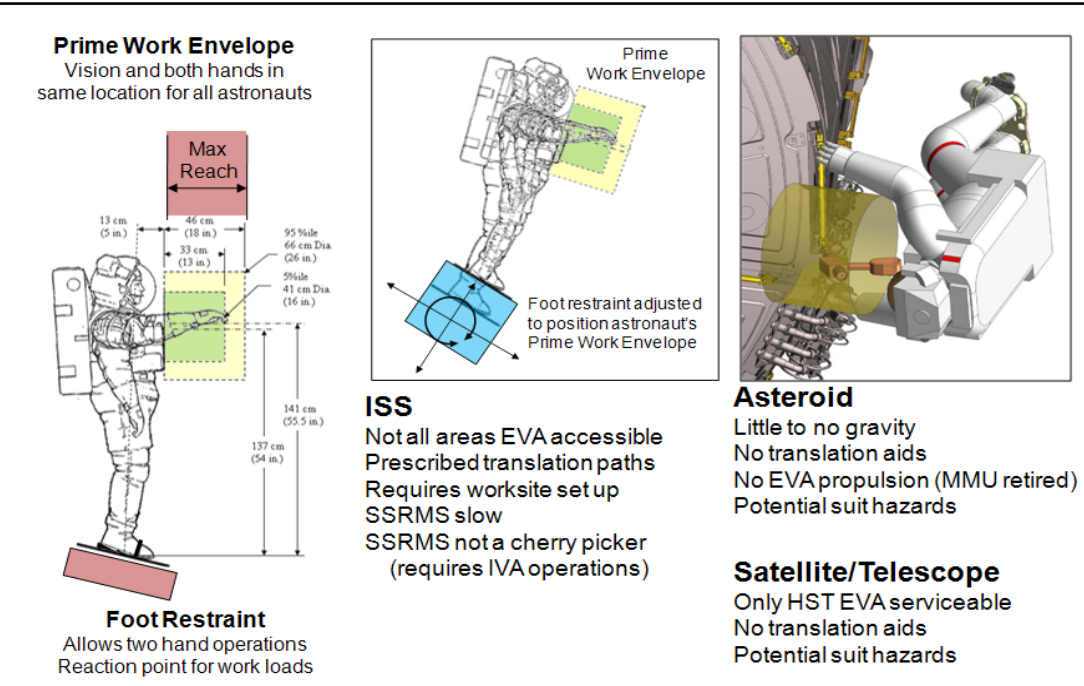

Figure 15 Properly positioned restraints necessary for weightless EVA 
"MMU can return to the airlock from the furthest point on Space Station (about $146.30 \mathrm{~m}(480 \mathrm{ft})$ ) in less than 1 minute."

MMU FlexCraft Performance

\begin{tabular}{|c|c|c|}
\hline & MMU & FlexCraft \\
\hline Delta V (m/s) & $20^{\circ}$ & $19.5^{* *}$ \\
\hline Nom. Range (m) & 137 & same \\
\hline Operation (hr) & 6 & same \\
\hline Propellant & GN2 & same \\
\hline Prop mass (kg) & 5.9 & 14.2 \\
\hline No. Thrusters & 24 & same \\
\hline Thrust (N) & 7.56 & same \\
\hline Tank Press (kpa) & 20,684 & 23,442 \\
\hline
\end{tabular}

Figure 16 MMU-FlexCraft Propulsion within the prime work envelope. For similar work, FlexCraft does not require pre-positioned foot restraints or a robotic arm. It flies to the site then, depending on the task, is stabilized using propulsive attitude hold or manipulators grasping adjacent structure. This approach reduces the worksite set up time and enables working in areas that are either not accessible by suited astronauts or lack provisions for restraint.

FlexCraft has integral propulsion and therefore can fly "directly" to the work site. Typically, a low energy trajectory is used to get to and from the work site, but for urgent situations, forced motion shortens the transit time at the expense of additional propellant consumption. FlexCraft can perform an emergency return from the most distant point on ISS in less than a minute. As shown in Figure 16, the FlexCraft propulsion system is the same as the flight-proven Manned Maneuvering Unit (MMU). The nitrogen tanks are larger to provide extended range, but have the same pressure as the MMU. In comparison, the translation time for EVA astronauts is affected by the suit configuration, tools carried, moving tethers and the pathway or landscape to the work site. Times recorded from an ISS Increment 9 task include: 9 minutes from hatch to Strella, 15 minutes to PMA1, 5 minutes to SO and 14 minutes for tool configuration and translation to the work site ${ }^{9}$. For ISS, the Space

Station Robotic Manipulator System (SSRMS) provides another method of translation that includes a mobile foot restraint for the EVA crew. It is slow, $15 \mathrm{~cm} / \mathrm{sec}(6 \mathrm{in} / \mathrm{sec})$ and because the EVA crew member does not have controls, it cannot be operated like a cherry picker on Earth ${ }^{10}$. Another crew member inside is required to operate the arm. For extended reach the SSRMS is attached to a mobile transporter that moves along the ISS truss segments. Because the transporter creeps along at $2.5 \mathrm{~cm} / \mathrm{sec}(1 \mathrm{in} / \mathrm{sec})$ it is used for cargo and not crew translation (Fig 17).

For human exploration of asteroids, there is a significant difference between FlexCraft and suited operations. Integral propulsion allows FlexCraft astronauts to fly directly between the host vehicle and asteroid as well as,

Slow: SSRMS for EVA support $15 \mathrm{~cm} / \mathrm{sec}^{1}$ Mobile Transporter is $2.5 \mathrm{~cm} / \mathrm{sec}^{2}$ (used for cargo) Important: EVAis time-constrained

Heavy: $1800 \mathrm{~kg}$ (Canadarm2, does not include MSS, Boom, MFR)

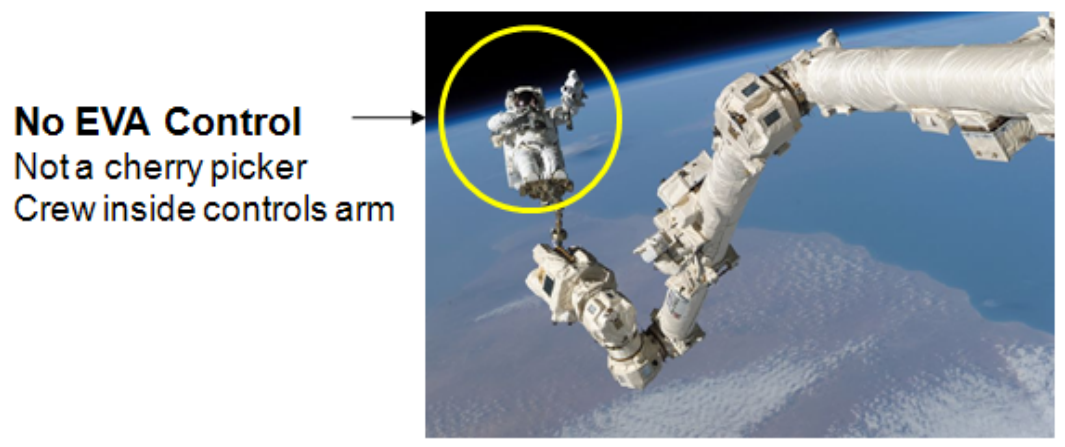

Figure 17 SSRMS is slow and requires an inside operator

conduct aerial surveys, hover and make repeated short excursions with different crew members. Because the vehicle remains outside, there is no risk of contaminating the interior with asteroid material, unlike airlock operations using suits. Recent studies have proposed different approaches for EVA exploration of asteroids. Some use a rear-entry suitport which isolates contamination, but still requires an airlock or cabin depressurization to bring the suit inside. For EVA 'translation" to the work site, some concepts use a MMU-like propulsion and others have astronauts on the end of robotic arms. Either option adds mass. The original MMU is no longer in NASA's flight inventory but if used, each one would weigh $150 \mathrm{~kg}$ (330.7 lb) not including external flight support station. A minimal 2 crew airlock like

\footnotetext{
${ }^{9}$ Extravehicular Activity Task Work Efficiency, C Looper and Z. Ney, SAE 2005-01-3014

${ }^{10}$ International Space Station, Robotics Group, Robotics Book, JSC 48540
} 
flown on the Shuttle weighs $440 \mathrm{~kg}(970 \mathrm{lb})$. And an arm similar to the ISS Canada Arm 2 would weigh $1800 \mathrm{~kg}$ (3968.3 lb). EVA operates with a buddy system which means a minimum of two suits and the current ISS EMU weighs approximately $136 \mathrm{~kg}$ (299 lb). Two suits plus two MMUs and a Shuttle airlock total $1012 \mathrm{~kg}$ (2226 lb). By comparison, FlexCraft is estimated to weigh less than $500 \mathrm{~kg}$ (1102 lb) (Fig. 18).

System Mass

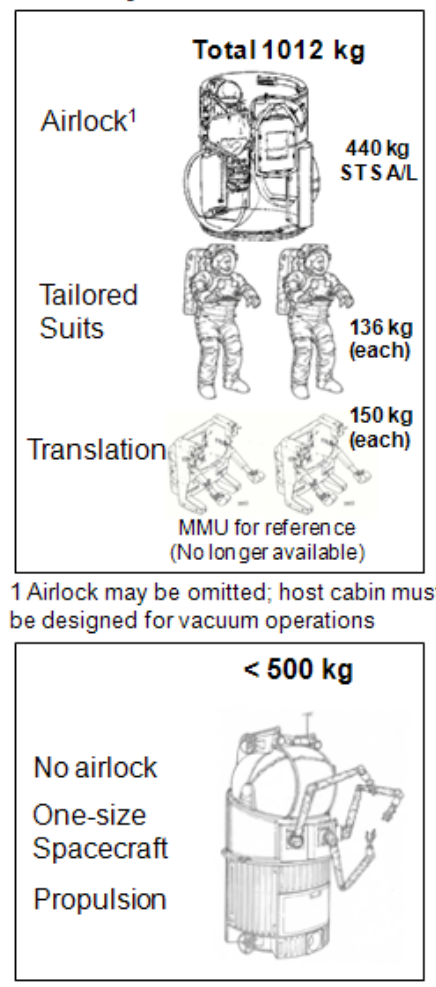

Contamination

EVAApproach

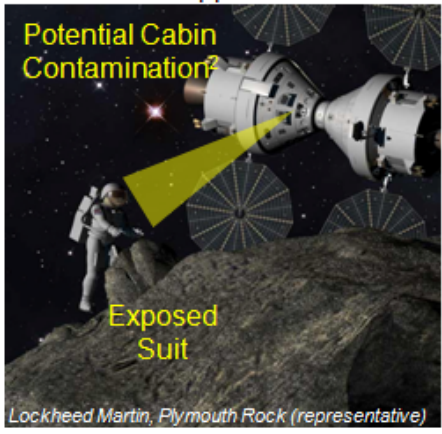

2 Suitport prevents contamination but suits remains outside without airlock capability

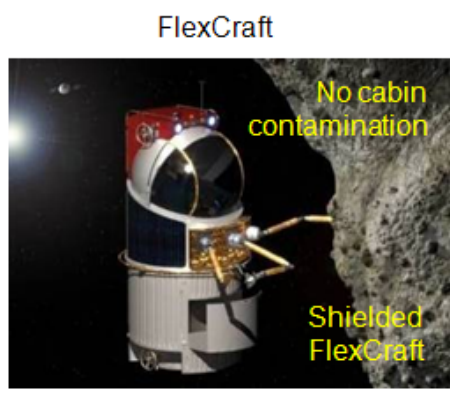

Figure 18 Airlock EVA and FlecCraft Mass

\section{Displays and Controls}

FlexCraft is specifically shaped for movement of the arms and hands providing access to internal controls and displays. Exploration and servicing missions cannot always be scripted so astronauts require ready access to different kinds of information. This includes geology for asteroids, schematics for servicing and procedures for repair. FlexCraft provides multiple flat panel color displays for access to on board information helping astronauts be more productive and safe. This capability is not an option when the communication to Earth prohibits timely discussions with ground resources. For space suits, the hands are the manipulators so grasping precludes simultaneous operations such as accessing controls. For FlexCraft, manipulators can grasp and hold thus freeing the hands for other operations. The EMU displays and controls are mounted externally on the chest and are operated with the pressurized glove. Some controls are out of view which means astronauts wear a mirror attached

to the sleeve to confirm settings. For displays, the EMU uses a 20 character LCD providing limited alpha-numeric information. There have been concepts for improved suit displays and controls, but none compare with the handsin, cockpit-type operations of a spacecraft (Figure 19).

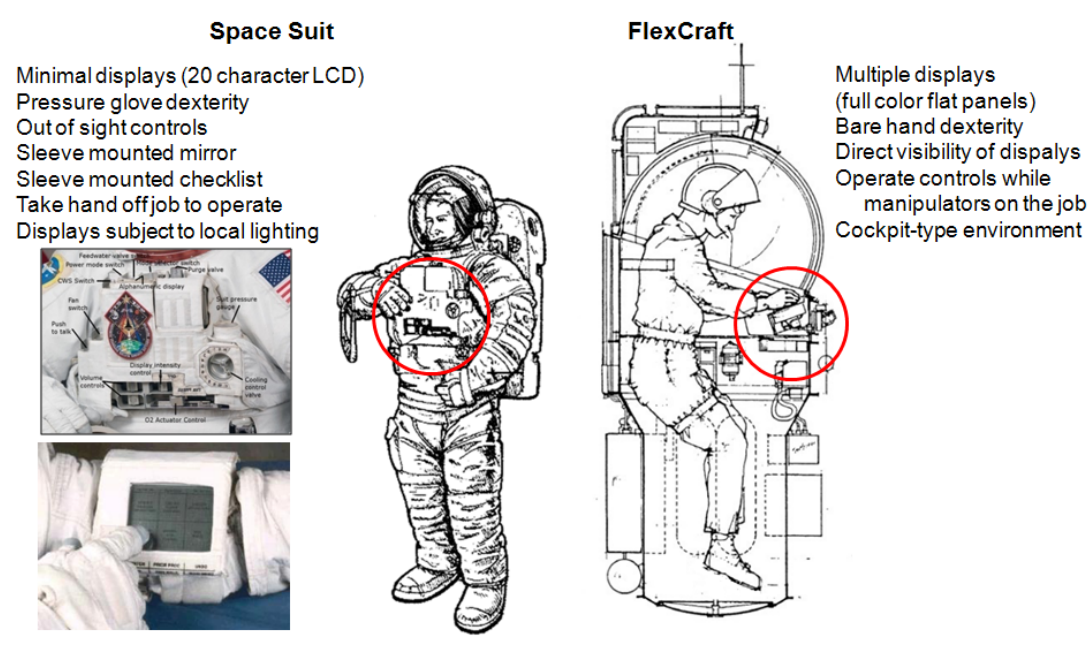

Figure 19 Internal displays and controls for exploration and servicing

\section{Nutrition and Hydration}

Working in a space suit is physically demanding and usually EVAs are at least 6 hours long. This is why the EMU is equipped with drinking water to compensate for sweating and food for nutrition. Because there is no way to bring the arms inside, astronauts have to use their mouth to access helmet mounted drink bag and food stick (Fig. 20). The food stick is a rice paper covered fruit and cereal bar designed to be eaten in one bite to prevent crumbs. Most astronauts prefer to eat before the EVA and not use the food stick. The in-suit drink bags hold 1.9 liters of water 


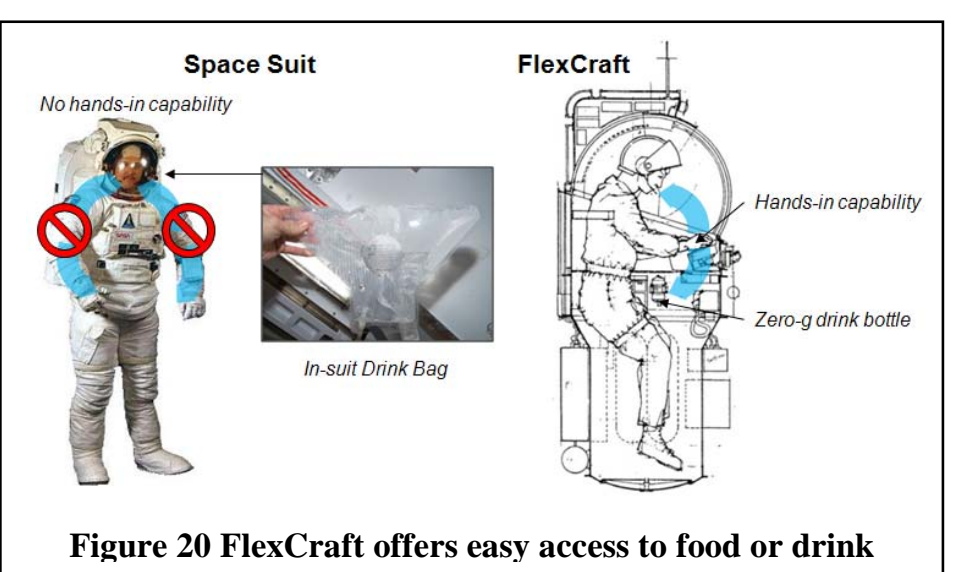

which is consumed by sucking on a straw-like tube. With hands-in capability, FlexCraft provides easy access to conventional weightless drink containers and food if desired. However, because the work is less demanding and short excursions are likely, astronauts may avoid taking food or drink to eliminate a potential "spill" or particulate contamination.

\section{N. Logistics and On-orbit Suit Sizing}

Space suits must be configured to fit each EVA astronaut. With approximately $41.2 \mathrm{~cm}$ (16.2 in.) difference in stature between the $1^{\text {st }}$ percentile female and $99^{\text {th }}$ percentile male (Fig. 21), different limb lengths, body

dimensions and crew preferences this is an extremely challenging job. To give a sense of the scale of space suit support, the current EVA contractor processes more than 500 components for the space suits and 250 tools used during planned Shuttle/ISS EVAs. ${ }^{11}$ For the suit pressure retention system alone there are 84 parts not including the gloves or backpack (Fig. 22). The Shuttle provided an excellent method of transporting EVA trained astronauts with their tailored space suits to ISS. Now, without the Shuttle, it becomes more complex to match properly sized suits with the ISS EVA crew. EVA suits are transported separately from the crew which means the on-orbit astronauts must have the inventory of parts to configure their suits for the particular EVA opportunity. The Shuttle was also effective in returning space suits to be used for future missions. Currently, there is no way to return space suits for reuse which means the

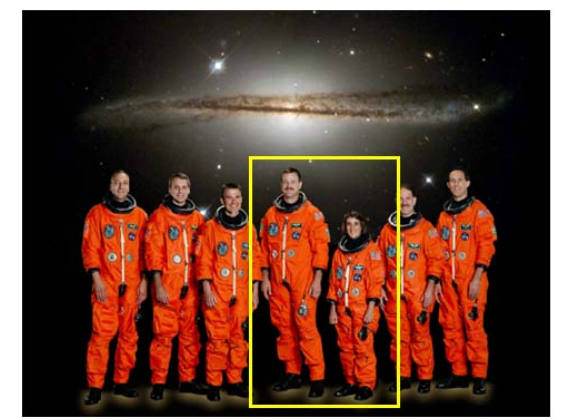

Figure 21 Crew Stature Difference

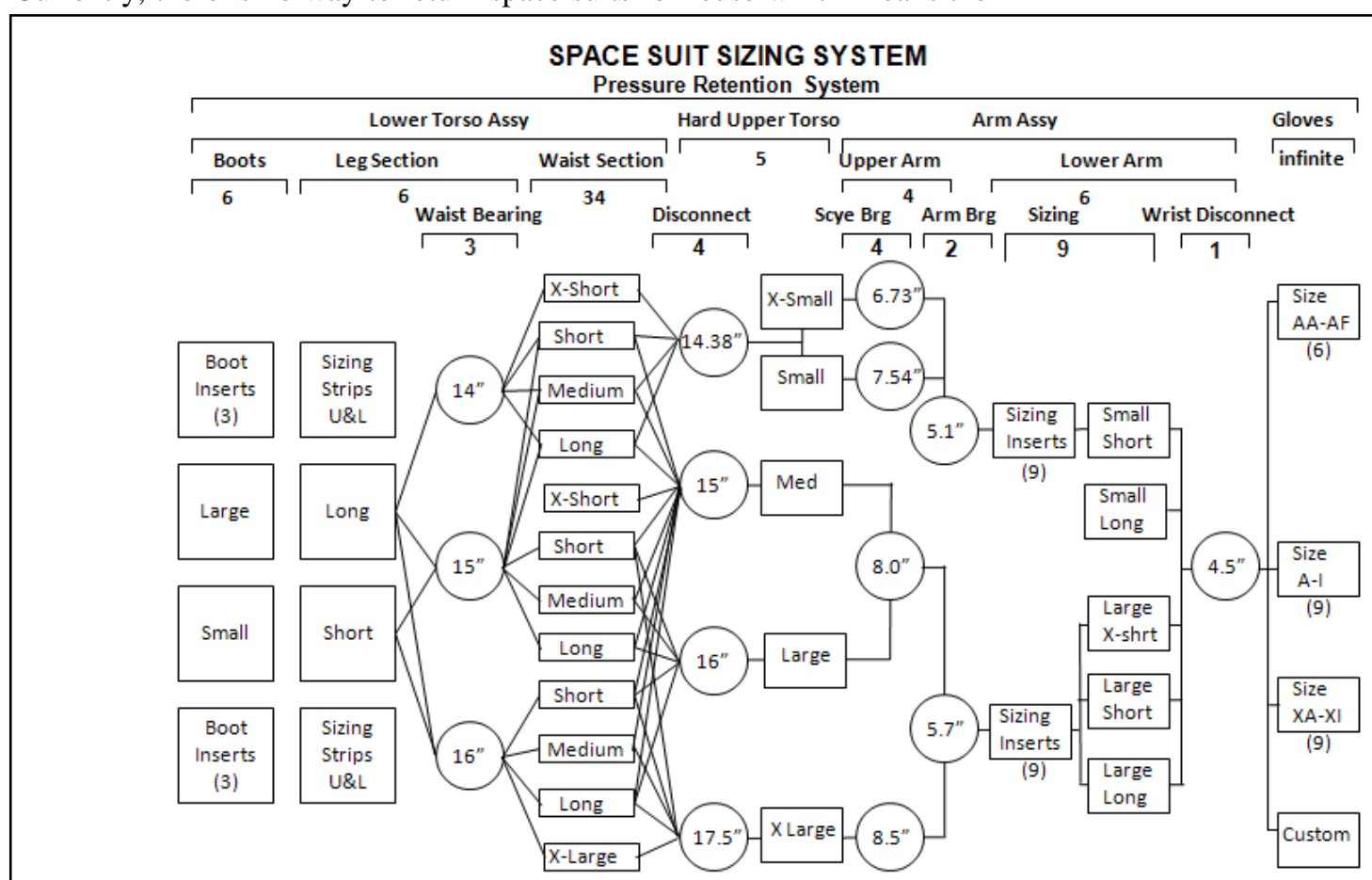

Fig. 22 Many space suit parts required to fit astronaut entire astronaut population

${ }^{11}$ http://www.unitedspacealliance.com/news/newsletters/issue066/Articles/CoverStory_ISS_Operations_ABridgetot heFuture.asp 
crew must have the skill, resources and parts for on-orbit servicing of suits and backpacks.

FlexCraft is designed to accommodate all crew with adjustable restraints that position the body for visibility, reach and comfort. Suits are maintained inside and FlexCraft is sized to fit through the $1.27 \mathrm{~m}$ (50 in.) ISS hatch opening for possible IVA servicing. Usually, FlexCraft remains outside and therefore incorporates features for selfservicing using its manipulators to inspect, service and replace subsystem Orbital Replacement Units.

\section{O. Development and Training}

Possibly one of the most significant differences with the biggest potential cost savings is in development and training. For weightless development, space suits use neutral buoyancy, parabolic aircraft and a flat floor. All require special conditions (e.g. water facility, aircraft, and precision flat floor) and are operated by specially trained personnel. Neutral buoyancy is used most often with NASA training done in the Neutral Buoyancy Laboratory (NBL). The NBL is the largest indoor water pool in the world and is supported by more than 200 employees, including 60 core divers ${ }^{12}$. A training session consists of two astronauts in suits weighted for neutral buoyancy along with safety divers, utility divers and control room personnel. The NBL has the support equipment and capability to conduct two simultaneous training sessions. For safety, personnel and equipment maintain current certification requirements and the facility has a hyperbaric chamber for treating the bends. The current contract to support the facility has a three-year base period is valued at \$67.6 million with two one-year options totaling \$52.3 million ${ }^{13}$.

In contrast, the FlexCraft approach uses proven aircraft-like simulation both for low-cost development of the vehicle and for follow-on training (Figure 23). Early development is done by engineers in conventional office

\section{Space Suits}
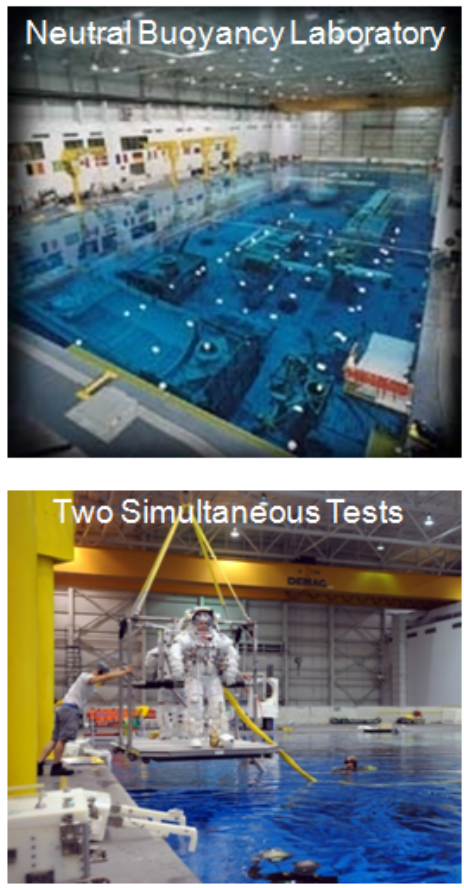

- Large unique facility

-Many skilled staff

Divers

Suit techs

Overhead crane

-Special equipment

-Many test personnel

-Safety issues

-Certification Training

-Pressurized gases

-Control room

-No on-orbit training

\section{FlexCraft}
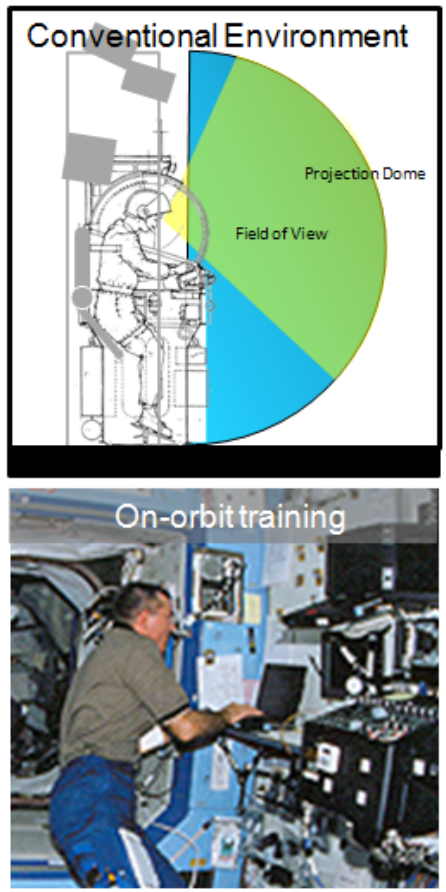

-Conventional Office

-Available projectors

-Available computers

-Simulation software

-Few test personnel

-No unique training

-No certification

-No safety issues

-On-orbit training

-Laptop platform

Figure 23 FlexCraft uses aircraft-like simulator development and training

environment, then as control and display concepts mature, a FlexCraft shell will be configured for operations assessment. This includes a form-fit mockup with immersive visualization. Like with aircraft, the operator inputs are linked to algorithms for accurate flight control around ISS, asteroids or other spacecraft. This approach is low cost because it does not require special facilities or unique safety certifications. It affords anytime access and emergency procedures can be performed without risk to hardware or personnel. Another important feature is that it is possible to maintain proficiency on-orbit with "laptop” simulations.

\footnotetext{
12 “Behind the Scenes Training,” NASA. May 30, 2003, Retrieved March 22, 2011

${ }^{13}$ CONTRACT RELEASE: C10-044, NASA Awards Neutral Buoyancy Laboratory, Space Vehicle Mockup Facility Support Contract
} 


\section{P. Case for Manipulators}

In recent years, manipulators have made significant advances (Fig. 24). They have earned their place in assembly and manufacturing; have contributed to important discoveries on Mars, are continuously working in the harsh submarine environment and are commonly used in cardiac, urologic and gynecologic surgery. In 2006, the daVinci surgical robotic system was used in over 48,000 procedures. At the Jet Propulsion Laboratory in 2011, a microspine end-effector demonstrated the ability to anchor to simulated asteroid material which then provided a work platform for core sample drilling. Another device by Altius Space Machines uses electroadhesion for grasping almost anything and has been tested in the vacuum chamber and weightlessness during parabolic flight. FlexCraft uses these technologies providing interchangeable manipulators and end-effectors that are configured for the task. Some will grasp and stabilize the spacecraft to react imparted loads and others will cut thin layers of insulation and connect wires. Unlike gloves, manipulators can be large or small, with small ones providing access where the gloved hand cannot go. There are also advantages in strength, continuous grasping, precision, repeatability and teleoperation. Without relying on muscles to hold a position, manipulators can be frozen in-place for operators to assess the next step. A summary comparison between manipulator and gloved operations in described in Fig. 25.

\begin{tabular}{|c|c|}
\hline Manipulator & Pressure Glove \\
\hline Direct mechanical connection & Gloved hand grips tool \\
\hline Programmable (exact repetition) & Imprecise and user dependent \\
\hline Many end-effectors available & EVA Tools transported to worksite \\
\hline \begin{tabular}{ll|} 
& Tele-operation \\
\end{tabular} & Not Applicable \\
\hline Not time dependent (freeze action for deliberation) & Time dependent (life support consumables) \\
\hline Insensitive to pressure & Higher pressure requires greater force \\
\hline Insensitive to temperature & Hot and cold boundary conditions \\
\hline No glove-induced trauma & Bruises and delaminated finger nails \\
\hline Mechanical advantage $=$ greater force & User dependent, limits to hand strength \\
\hline No force continuous grasping & Continuous force for grasping \\
\hline 360 degree rotary motion & Wrist rotates approximately 180 degrees \\
\hline Eye point at manipulator & Not possible (parallax) \\
\hline Not governed by fatigue & Fatigue from pressure suit and glove \\
\hline $\begin{array}{r}\text { Independent of user anthropometry arm length, } \\
\text { hand/finger size }\end{array}$ & $\begin{array}{l}\text { Dependent on user anthropometry suit sizing and } \\
\text { restraint location }\end{array}$ \\
\hline $\begin{aligned} \text { Physical conditioning not required } \\
\end{aligned}$ & Physical conditioning desired/required \\
\hline Multiple users (series or parallel) & Single user \\
\hline Learned, programmable operation & Training in simulated environment \\
\hline Adjustable force feed back & Glove design and pressure dependent \\
\hline
\end{tabular}

Figure 25 Manipulators are well suited for weightless operations
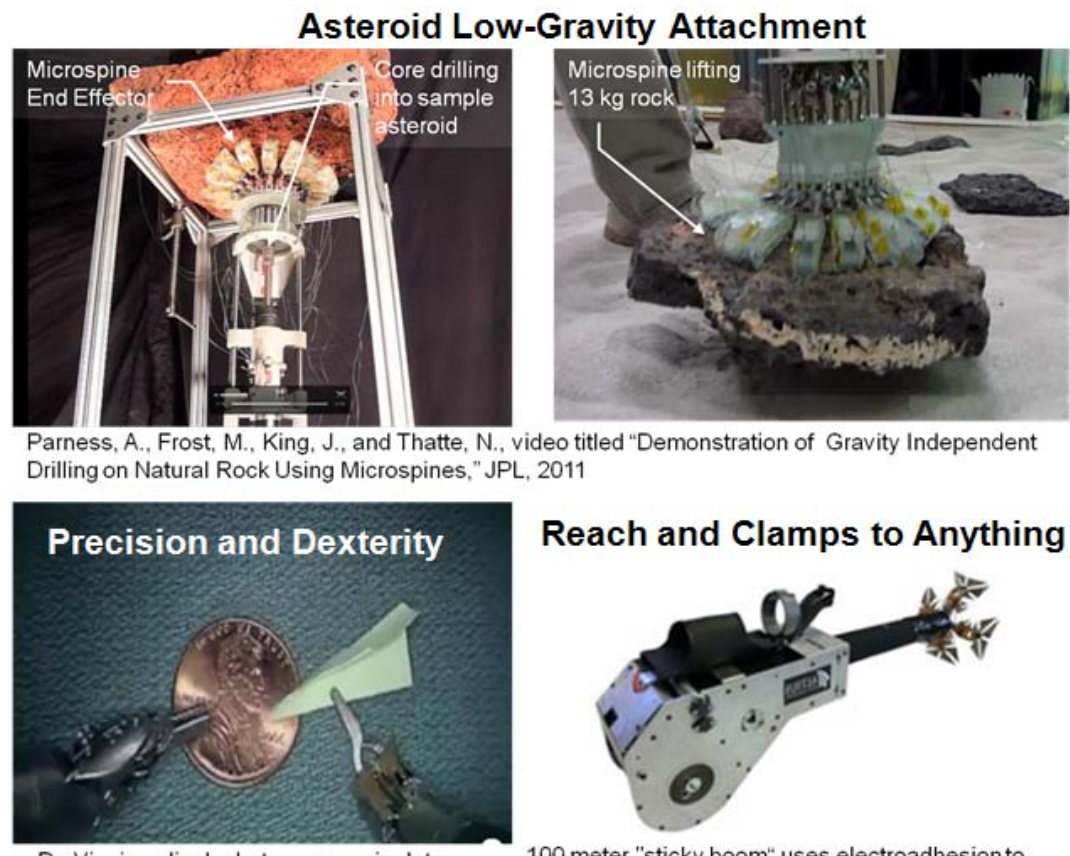

Da Vinci medical robot uses manipulators to fold small paper airplane

100 meter "sticky boom" uses electroadhesion to

clamp onto virtually anything (Altius Space Machines)

Reach and Clamps to Anything

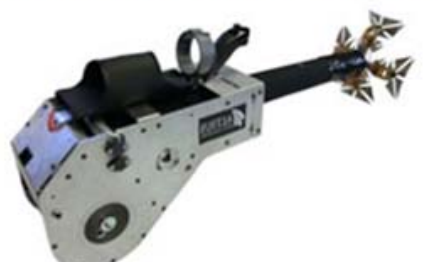

Figure 24 Manipulators do what pressure gloves cannot 


\section{Conclusions}

Why walk when you can fly? A single-person spacecraft offers compelling performance, cost and safety benefits over weightless spacewalking. With this capability, astronauts will transition from grabbing hand rails to piloting spacecraft; from lengthy preparations to rapid space access; from strenuous activity to cockpit operations; and from labor intensive neutral buoyancy training to flight-like simulators. FlexCraft requires no new technologies and provides immediate payback for maintaining an aging ISS and servicing satellites. There will be development and operational challenges, but the post-Shuttle era offers an ideal opportunity to invest in the benefits of a singleperson spacecraft for weightless operations.

\section{References}

Akin, David L. and Mary L. Bowden, "SCOUT: EVA Capabilities of the Space Construction and Orbital Utility Transport,"34th International Conference on Environmental Systems, Colorado Springs, CO, July 2004.

Cadogan, D., Bradley, D., and Kosmo, J., "Spacesuit Glove Manufacturing Enhancements Through the Use of Advanced Techniques," SAE 932102

Chodack, J., and Spampinato, P., "Spacesuit Glove Thermal Micrometeoroid Garment Protection Versus Human Factors Design Parameters,” SAE 911383

Chullen, C., McMann, J., Dolan, K., Bitterly, R., and Lewis, C., "U.S. Spacesuit Knowledge Capture,” AIAA 2011-5199

Chullen, C., Westheimer, D. T., "Extravehicular Activity Technology Development Status and Forecast.” AIAA 2011-5179

Dillon, P., Thomas, G., Oliver, J., and Zapata, F., "Flexible Packaging Concept for a Space Suit Portable Life Support Subsystem,” SAE 2009-01-2345

Extravehicular Mobility Unit Specification SVHS 7800, Rev BZ, pg 83, pg 84, Section 3.1.1.4.1

Fullerton, R. K., “Advanced EVA Roadmaps and Requirements,” ICES01-2200

http://www.unitedspacealliance.com/news/newsletters/issue066/Articles/CoverStory_ISS_Operations_ABridget otheFuture.asp

International Space Station, Robotics Group, Robotics Book, JSC 48540

Looper, C., and Ney, Z., “Extravehicular Activity Task Work Efficiency,” SAE 2005-01-3014

Man Systems Integration Standard, Volume I, Section 14 EXTRAVEHICULAR ACTIVITY (EVA)

Newman, D. and Barratt, M., "D.J. Newman and M. Barratt, Chapter 22: "Life Support and Performance Issues for Extravehicular Activity (EVA)," Fundamentals of Space Life Sciences, S. Churchill, ed., Krieger Publishing Co., Melbourne, Florida, 1997

Opperman RA, Waldie JM, Natapoff A, Newman DJ, Jones JA, "Probability of Spacesuit-induced Fingernail Trauma is Associated with Hand Circumference," Aviation Space Environmental Medicine, 2010 Oct; 81(10):90713

Parness, A., Frost, M., King, J., and Thatte, N., video titled "Demonstration of Gravity Independent Drilling on Natural Rock Using Microspines,” JPL, 2011

Safety Standard for Oxygen and Oxygen Systems, NASA, NSS 1740.15, January 1996 , Flammability, Offgassing, and Compatibility Requirements and Test Procedures, NASA-STD-6001B, Aug 26, 2011

Thomas, K. S., and H. J. McMann, H. J., US Spacesuits, Springer Publishing Ltd, Chichester, UK, 2006

Whitsett, C. E., "Role of the Manned Maneuvering Unit for the Space Station," , SAE 861012

Walz, C., and Gernhardt, M., "Extravehicular Activity - Challenges in Planetary Exploration,” February, 2008, Third Space Exploration Conference and Exhibit, Denver, CO

Decompression Sickness, Undersea Hypobaric Medical Society, 2007 